\title{
Rapid progression of prostate cancer in men with a BRCA2 mutation
}

\begin{abstract}
SA Narod ${ }^{*, 1}$, S Neuhausen ${ }^{2}$, G Vichodez', S Armel $^{3}$, HT Lynch ${ }^{4}$, P Ghadirian $^{5}$, S Cummings $^{6}$, O Olopade $^{6}$, D Stoppa-Lyonnet ${ }^{7}$, F Couch $^{8}$, T Wagner', E Warner ${ }^{10}$, WD Foulkes ${ }^{11}$, H Saal ${ }^{12}$, J Weitzel ${ }^{13}$, A Tulman', A Poll', R Nam ${ }^{10}$ and P Sun', the Hereditary Breast Cancer Study Group ${ }^{14}$

'Women's College Research Institute, 790 Bay Street, 7th Floor, Women's College Hospital, University of Toronto, Toronto, Ontario, Canada; ${ }^{2}$ Department of Epidemiology, University of California, Irvine, USA; ${ }^{3}$ University Health Network, Toronto, Ontario, Canada; ${ }^{4}$ Department of Preventive Medicine and Public Health, Creighton University School of Medicine, Omaha, NE, USA; ${ }^{5}$ Epidemiology Research Unit, Research Centre, Centre Hospitalier de l'Universitaire Montréal, CHUM Hôtel Dieu, Montreal, Quebec, Canada; ${ }^{6}$ Chicago Center for Clinical Cancer Genetics, University of Chicago, Chicago, IL, USA; ${ }^{7}$ Institut Curie, Paris, France; ${ }^{8}$ Mayo Clinic, Rochester, MN, USA; ${ }^{9}$ Department of Gynecology, Division of Senology, Medical University of Vienna and Private Trust for Breast Health, Vienna, Austria; ${ }^{10}$ Sunnybrook Regional Cancer Center, Toronto, Ontario, Canada; ' Departments of Medicine and Oncology, McGill University, Montreal, Quebec, Canada; ${ }^{12}$ Hereditary Cancer Program, Division of Human Genetics, Children's Hospital Medical Center, Cincinnati, OH, USA; ${ }^{13}$ City of Hope Department of Cancer Genetics, City of Hope National Medical Center, Duarte, CA, USA
\end{abstract}

Men with BRCA2 mutations have been found to be at increased risk of developing prostate cancer. There is a recent report that $B R C A 2$ carriers with prostate cancer have poorer survival than noncarrier prostate cancer patients. In this study, we compared survival of men with a BRCA2 mutation and prostate cancer with that of men with a BRCAI mutation and prostate cancer. We obtained the age at diagnosis, age at death or current age from 182 men with prostate cancer from families with a BRCA2 mutation and from 119 men with prostate cancer from families with a BRCA / mutation. The median survival from diagnosis was 4.0 years for men with a BRCA2 mutation vs 8.0 years for men with a BRCA I mutation, and the difference was highly significant $(P<0.0 \mathrm{I})$. It may be important to develop targeted chemotherapies to treat prostate cancer in men with a BRCA2 mutation.

British Journal of Cancer (2008) 99, 37I-374. doi: I 0.1038/sj.bjc.6604453 www.bjcancer.com

Published online 24 June 2008

(C) 2008 Cancer Research UK

Keywords: prostate cancer; BRCA I; BRCA2

$B R C A 2$ is a multisite cancer gene. It is generally thought that $B R C A 2$ mutations primarily affect women, but men with mutations are also at elevated cancer risk. The two most important cancer sites for males who carry a mutation are the prostate and the pancreas (Liede et al, 2004). The risk of prostate cancer is elevated approximately fivefold in $B R C A 2$ carriers, compared to noncarriers. Genetic counselors and urologists advise men with $B R C A 2$ mutations to undergo surveillance with annual PSA testing from the age of 40 years - a recommendation based on the perceived effectiveness of prostate screening. It is hoped that screening leads to early diagnosis, when cure rates are high. A recent study from

\footnotetext{
* Correspondence: Dr SA Narod, Women's College Research Institute, Women's College Hospital, University of Toronto, 790 Bay Street, 7th Floor, Toronto, Ontario, Canada MSG IN8;

E-mail: steven.narod@wchospital.ca

${ }^{14}$ Other members of the Hereditary Breast Cancer Study Group: Jessica Danquah, Susan Domchek, Nadine Tung, Peter Ainsworth, Douglas Horsman, Charmaine Kim-Sing, Christine Maugard, Andrea Eisen, Mary Daly, Wendy McKinnon, Marie Wood, Claudine Isaacs, Dawna Gilchrist, Beth Karlan, Raluca Nedelcu, Wendy Meschino, Judy Garber, Barbara Pasini, Siranoush Manoukian, Christina Bellati.

Revised 24 April 2008; accepted 8 May 2008; published online 24 June 2008
}

Iceland suggests that prostate cancers in men with a BRCA2 mutation may be unusually aggressive (Tryggvadottir et al, 2007). Tryggvadottir et al (2007) identified the Icelandic founder mutation (BRCA2 999 del5) in 30 of the 527 prostate cancer patients studied (5.7\%). Men with a BRCA2 mutation had a median survival of only 2.1 years, compared with 12.4 years for noncarriers $(P<0.01)$. The survival difference could not be explained by stage or grade. It is important that these findings be replicated because of the implications for the screening of men with a BRCA2 mutation. We identified the prostate cancer patients in a panel of 2673 families with a $B R C A 1$ or a $B R C A 2$ mutation and estimated survival of the men in the two subgroups.

\section{METHODS}

Men with prostate cancer were included in the survival analysis if they were from a family with a BRCA mutation and if they were (a) known to carry the familial BRCA mutation, or (b) if they were a first-degree relative of a known carrier, or (c) if they were a firstdegree relative of a woman diagnosed with breast or ovarian cancer. For each eligible man with prostate cancer, information was collected on age at diagnosis, age at death (if deceased) or age when last known alive (if alive). Information was collected by the 
review of the family pedigree and the medical record of the proband. In some cases, this was supplemented by the interview of another family member. Men who had been diagnosed with other forms of cancer were excluded.

We identified 938 families with a BRCA2 mutation in the database. These families came from 33 different clinical centres in five countries. Of these, 277 families contained one or more cases of prostate cancer $(29.5 \%)$. In aggregate, the 277 families included 434 men with prostate cancer (mean 1.6 per family). In all 141 of the cases were ineligible (either known to be a noncarrier, married in, not closely related to a carrier or an affected woman or had a history of cancer other than prostate). Of the remaining 293 prostate cancer patients, we obtained data on age at diagnosis and age at death (or current age if alive) on $183(62 \%)$. Of these, 67 were determined to carry the familial BRCA2 mutation and 116 men were probable mutation carriers.

Men from families with BRCA1 mutations were selected as the comparison group. To ensure comparability, we used the same inclusion criteria as were used for the BRCA2 carriers. We identified 1735 families with a BRCA1 mutation, of which 316 families contained one or more cases of prostate cancer $(18.2 \%)$. The 316 families included 457 men with prostate cancer (a mean of 1.4 per family). A total of 252 of the cases were ineligible (either known to be a noncarrier, married in, not closely related to a carrier or an affected woman or had a history of cancer other than prostate); of the remaining 205 patients, we had data on age at diagnosis and age at death (or current age if alive) on 119 men $(58 \%)$. Of these, 37 were determined to carry the familial $B R C A 1$ mutation and 82 men were likely to be a carrier.

We performed survival analysis to establish the overall survival of BRCA2 mutation carriers with prostate cancer and the relative survival as compared to BRCA1 carriers. Patients were followed from the year of diagnosis until year of death (if deceased) or year when last known alive (in most cases 2007). Kaplan-Meier methods were used to construct survival curves, and the significance of the comparison of the curves was based on the log-rank test. A hazard ratio was estimated using the Cox proportional hazards model implemented in SAS version 9.1.3 version The hazard ratio was adjusted for age of diagnosis.

\section{RESULTS}

There were 183 men with prostate cancer who were known or probable carriers of a $B R C A 2$ mutation and 119 men with prostate cancer who were known or probable carriers of a BRCA1 mutation. The average age of diagnosis was similar for men in the two groups (Table 1). The median survival time was 8.0 years for $B R C A 1$ carriers (or probable carriers) and was 4.0 years for $B R C A 2$ carriers (or probable carriers) (Figure 1). The 5-year overall survival was $57 \%$ for $B R C A 1$ carriers and was $39 \%$ for $B R C A 2$ carriers. The 10 -year survival was $47 \%$ for $B R C A 1$ carriers and $25 \%$ for $B R C A 2$ carriers. The 15 -year overall survival was $35 \%$ for $B R C A 1$ carriers and $12 \%$ for $B R C A 2$ carriers. We estimated the hazard ratio for all-cause mortality for BRCA2 vs BRCA1 carriers, adjusted for age, over the entire follow-up period. We found that the risk of dying in cases from BRCA2 families was 70\% higher than in cases from BRCA1 families $(\mathrm{HR}=1.7 ; 95 \%$ CI $1.2-2.4)$ (Table 2).

The analysis was then repeated, including only known carriers (67 BRCA2 and 37 BRCA1). The median survival time was 15 years for carriers of a $B R C A 1$ mutation and was 5.0 years for carriers of a $B R C A 2$ mutation (Figure 2). The 5-year overall survival was $64 \%$ for $B R C A 1$ carriers and $42 \%$ for $B R C A 2$ carriers. The 10 -year survival was $60 \%$ for $B R C A 1$ carriers and $26 \%$ for $B R C A 2$ carriers. The 15 -year overall survival was $50 \%$ for $B R C A 1$ carriers and $4 \%$ for $B R C A 2$ carriers. We estimated the hazard ratio for all-cause mortality for $B R C A 2$ vs $B R C A 1$ carriers, adjusted for age, over the
Table I Characteristics of study subjects

\begin{tabular}{|c|c|c|c|}
\hline Variables & $\begin{array}{c}\text { BRCAI } \\
\mathbf{N}=\text { I I9 }(37 \\
\text { known carriers })\end{array}$ & $\begin{array}{c}\text { BRCA2 } \\
N=183(67 \\
\text { known carriers })\end{array}$ & $P$ \\
\hline \multicolumn{4}{|c|}{ Age at diagnosis (range) } \\
\hline All subjects & $66.9(4 \mid-86)$ & 67.1 (32-97) & 0.87 \\
\hline Known carriers & $70.2(55-86)$ & $67.1(49-84)$ & 0.08 \\
\hline \multicolumn{4}{|l|}{ Vital status N (\%) } \\
\hline \multicolumn{4}{|l|}{ All subjects } \\
\hline Alive & $72(60.5)$ & $67(36.6)$ & \\
\hline Dead & $47(39.5)$ & $116(63.4)$ & $<0.0001$ \\
\hline \multicolumn{4}{|l|}{ Known carriers } \\
\hline Alive & $24(64.9)$ & $24(35.8)$ & \\
\hline Dead & $13(35.1)$ & $43(64.2)$ & 0.004 \\
\hline \multicolumn{4}{|c|}{ Mean follow-up years (range) } \\
\hline All subjects & $4.3(0-15)$ & $4.1(0-15)$ & 0.74 \\
\hline Known carriers & $5.7(0-15)$ & $4.3(0-10)$ & 0.14 \\
\hline
\end{tabular}

Table 2 All cause mortality in BRCA2 vs BRCA / patients with prostate cancer

\begin{tabular}{|c|c|c|c|c|}
\hline & \multicolumn{2}{|c|}{ Univariate } & \multicolumn{2}{|c|}{ Age-adjusted } \\
\hline & HR (95\% Cl) & $P$ & HR (95\% Cl) & $P$ \\
\hline $\begin{array}{l}\text { BRCA2 vs BRCA I } \\
\text { All subjects }\end{array}$ & $1.64(1.17-2.30)$ & 0.005 & $1.7 \mid(\mid .22-2.41)$ & 0.002 \\
\hline $\begin{array}{l}\text { BRCA2 vs BRCA I } \\
\text { Known carriers }\end{array}$ & $2.41(1.28-4.52)$ & 0.006 & $2.48(1.31-4.70)$ & 0.005 \\
\hline
\end{tabular}

Hazard ratio represents mortality experience of patients with BRCA2 mutation compared to those with BRCAI mutations, calculated using Cox proportional hazards model.

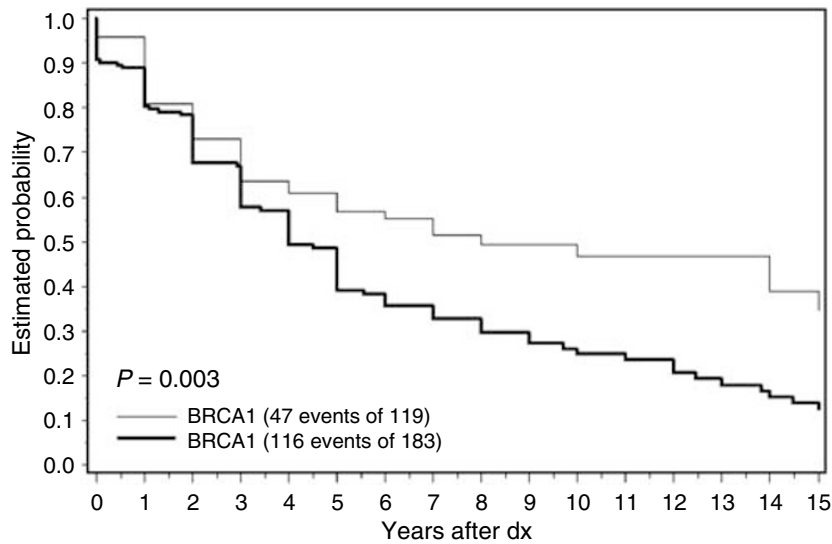

Figure I Probability of survival after prostate cancer in men from families with BRCAI and BRCA2 mutations (all causes of death).

entire follow-up period. The hazard ratio was 2.5 (95\% CI 1.3-4.7; $P=0.005)$.

\section{DISCUSSION}

In this study, we examined survival for men with prostate cancer and a BRCA2 mutation, and compared this to a similar group of men with a BRCA1 mutation. Prostate cancer is a clinical 


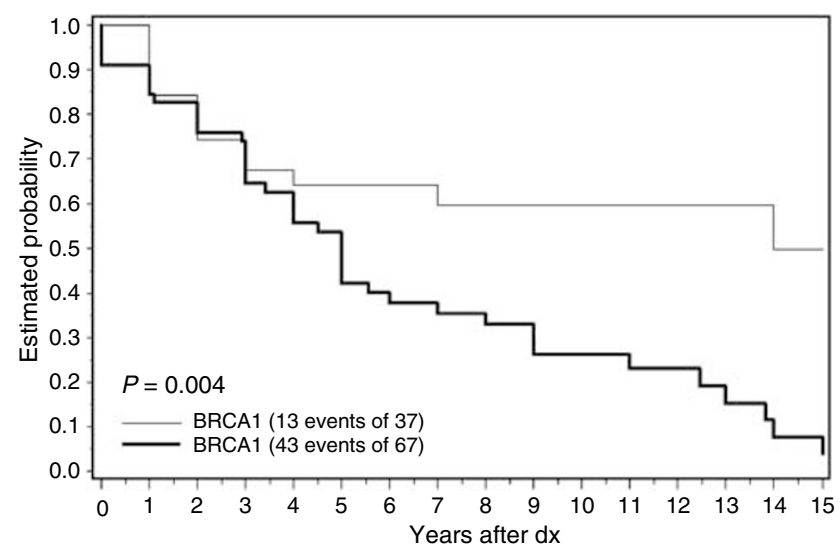

Figure 2 Probability of survival after prostate cancer in known carriers with BRCAI and BRCA2 (all causes of death).

manifestation of the BRCA2 gene, but only a small proportion of prostate cancers are attributable to $B R C A 2$ mutations. An excess risk of prostate cancer among men with BRCA2 mutations has been previously documented. Epidemiology studies have been of two types: (1) estimating the risk of prostate cancer in men from families with $B R C A 2$ mutations, and (2) estimating the proportion of $B R C A 2$ mutations among unselected men with prostate cancer. In a study of 173 families with $B R C A 2$ mutations, the Breast Cancer Linkage Consortium reported in 1999 that there was a significantly increased risk of prostate cancer among male first-degree relatives of female carriers (Breast Cancer Linkage Consortium, 1999). They estimated the odds ratio to be 4.7 (95\% CI 3.5-56.2). In a study in the Netherlands of 139 families with BRCA2 mutations, Van Asperen et al (2005) confirmed an excess risk of prostate cancer in first-degree relatives of carriers ( $\mathrm{OR}=2.5$; 95\% CI 1.6-3.8). Given that only one-half of the first-degree relatives are expected to be gene carriers, this corresponds to a relative risk of prostate cancer, given a BRCA2 mutation, of approximately five.

Kirchoff et al (2004) tested 251 unselected Ashkenazi Jewish men with prostate cancer from the New York area for the two founder mutations in BRCA1 and the one in BRCA2. They also tested 1472 Ashkenazi controls. A mutation was found in $5.2 \%$ of cases and $1.9 \%$ of controls. The presence of a BRCA2 mutation was associated with a 4.8 -fold increased risk of prostate cancer. In contrast, the BRCA1 carriers in that study were not at increased risk of prostate cancer. In a study from the United States, Agalliu et al (2007) found a BRCA2 mutation in two of 290 men diagnosed with prostate cancer under the age of 55 (mixed ethnicities). The relative risk for early-onset prostate cancer was 7.8.

We observed that men with prostate cancer and a BRCA2 mutation experienced relatively poor survival, in comparison to men with prostate cancer and a $B R C A 1$ mutation. The median survival for $B R C A 2$ carriers was 4.0 years, and at 10 years post-diagnosis, $53 \%$ of the patients had died.

There are several limitations to our study. Ideally, one would follow a cohort of unselected patients with prostate cancer and a $B R C A 2$ mutation, record details on the stage, grade and all treatments received, and then compare the outcome of the hereditary group with a similar group of patients without a mutation. We do not know the cause of death for these patients and expect that some will have died of causes other than prostate cancer. Not all of the patients in our study were proven carriers of a BRCA2 mutation; we included 67 carriers (or obligate carriers) and 116 men with prostate cancer who had not been tested for the presence of the mutation. The families in this study were those referred to various cancer genetics centres because of multiple cases of breast and/or ovarian cancer in the family, and were not selected on the basis of prostate cancer. The demographic and clinical information on the patients with prostate cancer were taken from a pedigree review and interview of the proband; we did not review the medical record or the pathology report of the prostate cancer patient. The ages of diagnosis and death were based on information provided by the female proband. It may be probable that not all cases of prostate cancer in male relatives were recorded. We do not know if the case was diagnosed clinically or through prostate cancer screening. We do not have information on the stage or grade at presentation, and we did not record details of treatment.

Despite these numerous limitations, we believe that the differences observed in survival of the $B R C A 1$ and $B R C A 2$ carriers (Figures 1 and 2) can be attributed to the adverse effect of the $B R C A 2$ mutation on prostate cancer survival. These data were recorded and collected using the same methods for the BRCA1 and $B R C A 2$ families. There is no reason to believe that carriers of $B R C A 2$ mutations should have greater mortality than men with $B R C A 1$ mutations from non-cancer causes, and men with other forms of cancer were excluded. The survival experience of the $B R C A 2$ carriers is almost universally poor, as only $26 \%$ of the known carriers were alive 10 years after diagnosis and $4 \%$ were alive at 15 years. Compared to men with a BRCA1 mutation, men with a BRCA2 mutation in this study were more than two times as likely to die (of any cause) following the diagnosis of prostate cancer (hazard ratio 2.5 ), and it is likely that the relative mortality for prostate cancer-specific mortality would be even more extreme. These data support the conclusions of Tryggvadottir et al (2007) who reported that men with prostate cancer and a BRCA2 mutation experienced an unexpectedly high rate of mortality. The basis for the aggressive behaviour of the BRCA2-associated prostate cancers is not known. Moro et al (2008) show that downregulation of BRCA2 expression through the introduction of siRNA in prostate cancer cells promoted cancer cell migration and invasion. Mitra et al (2008) found the average grade of prostate cancers among men with BRCA2-associated prostate cancers (Gleason score) to be higher than that of noncarrier control tumours.

We compared the survival of men with $B R C A 2$ mutations with that of men with BRCA1 mutations. Ideally, we would have included a comparison group of noncarriers as well. However, it was not possible to identify a similar group of noncarrier patients from this database, given that we routinely collect pedigree information only on families with a mutation in one of the two genes. Although we do not have a comparable group of noncarriers in this study, it has been reported in a trial of patients undergoing watchful waiting $v s$ prostatectomy that $27 \%$ of men with prostatectomy died within 10 years of diagnosis (all-cause mortality) and $32 \%$ of men with watchful waiting died within 10 years of diagnosis (Bill-Axelson et al, 2005). In comparison, $75 \%$ of the BRCA2 carriers in our study died within 10 years of diagnosis.

If survival in BRCA1 carriers is atypical, then our observed difference will not be representative of prostate cancer in general. To our knowledge, BRCA1 is not associated with an improved survival experience. Furthermore, the risk of prostate cancer in $B R C A 1$ carriers is increased only to a small extent, if any (Kirchoff et al, 2004; Cybulski et al, 2008), and an increased risk is not associated with all mutations (Cybulski et al, 2008). Therefore, we expect the survival experience of men with prostate cancer in $B R C A 1$ families to be similar to that of the general population.

The data from the two studies suggest that men with BRCA2 mutations may not benefit from current therapies to the same extent as other men. We do not know which men in this cohort had screen-detected prostate cancer, and it will be important to study whether or not men who have subclinical, screen-detected prostate cancer also experience a high mortality rate. To address this issue, we plan to identify the BRCA2 carriers among a large sample of prostate cancer patients and to characterise them in 
terms of clinical presentation, pathology and response to treatment. Future studies should also address whether current surgical and non-surgical treatments improve survival from prostate cancer among $B R C A 2$ carriers. Current treatments include surgery, hormonal-based therapies and radiotherapy. Given that the $B R C A 2$ protein is involved in the repair of damaged DNA breaks, and that radiation induces double-strand breaks, it is possible that prostate cancer patients with a $B R C A 2$ mutation are more sensitive to radiotherapy than patients without a mutation. Cytotoxic chemotherapy is not generally used in the early treatment of prostate cancer. Currently, there is interest in identifying directed treatments for breast cancer in $B R C A 1$ and $B R C A 2$ carriers. Drugs that induce DNA-strand breaks, such as cis-platinum, show increased sensitivity in pre-clinical models,

\section{REFERENCES}

Agalliu I, Karlines E, Kwon EM, Iwasaki LM, Diamond A, Ostrander EA, Stanford JL (2007) Rare germline mutations in the BRCA2 gene are associated with early-onset prostate cancer. Br J Cancer 97: 826-831

Bill-Axelson A, Holmberg L, Ruutu M, Häggman M, Andersson SO, Bratell S, Spångberg A, Busch C, Nordling S, Garmo H, Palmgren J, Adami HO, Norlén BJ, Johansson JE, for the Scandinavian Prostate Cancer Group Study No. 4 (2005) Radical prostatectomy $v s$ watchful waiting in early prostate cancer. N Engl J Med 352: 1977-1984

Breast Cancer Linkage Consortium (1999) Cancer risks in BRCA2 mutation carriers. J Natl Cancer Inst 91: 1310-1316

Cybulski C, Górski B, Gronwald J, Huzarski T, Byrski T, Debniak TA, Wokolorczyk D, Gliniewicz B, Sikorski A, Stawicka M, Godlewski D, Kwias Z, Antczak A, Krajka K, Lauer W, Sosnowski M, Sikorska-Radek P, Bar K, Klijer R, Romuald Z, Malkiewicz B, Borkowski A, Borkowski A, Szwiec M, Posmyk M, Narod SA, Lubinski J (2008) BRCA1 mutations and prostate cancer in Poland. Eur J Cancer Prev 17: 62-66

Kirchoff T, Kauff NN, Mitra N, Nafa K, Huang H, Palmer C, Gulati T, Wadsworth E, Donat S, Robson ME, Ellis NA, Offit K (2004) BRCA mutations and risk of prostate cancer in Ashkenazi Jews. Clin Cancer Res 10: $2918-2921$ and trials are now underway to study cis-platinum and PARP1 inhibitors in women with breast cancer and a BRCA mutation. A male patient with metastatic prostate cancer and a BRCA2 mutation has responded well to a PARP1 inhibitor (A Tutt, J De Bono, personal communication). It will be a matter of considerable interest to see whether or not the men with prostate cancer and a $B R C A 2$ mutation benefit from targeted chemotherapy.

\section{ACKNOWLEDGEMENTS}

Supported by the Canadian Breast Cancer Research Alliance. SLN was supported by NIH CA744175.
Liede A, Karlan B, Narod SA (2004) Cancer risks for male carriers of germline mutations in BRCA1 or BRCA2: a review of the literature. J Clin Oncol 22: $735-742$

Mitra A, Fisher C, Foster CS, Jameson C, Barbachanno Y, Bartlett J, Bancroft E, Doherty R, Kote-Jarai Z, Peock S, Easton D, Eeles R, IMPACT and EMBRACE Collaborators (2008) Prostate cancer in male BRCA1 and BRCA2 mutation carriers has a more aggressive phenotype. Br J Cancer 98: 502-507

Moro L, Arbini AA, Yao JL, di Sant'Agnese PA, Marra E, Greco M (2008) Loss of BRCA2 promotes prostate cancer cell invasion through upregulation of matrix metalloproteinase-9. Cancer Sci 99: 553-563

Tryggvadottir L, Vidarsdottir L, Thorgeirsson T, Jonasson JG, Ólafsdóttir EJ, Ólafsdóttir GH, Rafnar T, Thorlacius S, Jonsson E, Eyfjord JE, Tulinius H (2007) Prostate cancer progression and survival in BRCA2 mutation carriers. J Natl Cancer Inst 99: 908-909

Van Asperen $\mathrm{CH}$, Brohet RM, Meijers-Heijboer EJ, Hoogerbrugge N, Verhoef S, Vasen HFA, Ausems MGEM, Menko FH, Gomez Garcia EB Klijn JGM, Hogervorst FBL, van Houwelingen JC, van't Veer LJ, Rookus MA, van Leeuwen FE on behalf of the Netherlands Collaborative Group on Hereditary Breast Cancer (2005) Cancer risks in BRCA2 families: estimates for sites other than breast and ovary. J Med Genet 42: $711-719$ 